DOE/AL/62350-193

REV. 0

\title{
UMTRA GROUND WATER SAMPLING TECHNIQUES: COMPARISON OF THE TRADITIONAL AND LOW FLOW METHODS
}

\author{
RECEIVED \\ AUG 151995 \\ OSTI
}

July 1995

\section{DISCLAIMER}

This report was prepared as an account of work sponsored by an agency of the United States Government. Neither the United States Government nor any agency thereof, nor any of their employees, makes any warranty, express or implied, or assumes any legal liability or responsibility for the accuracy, completeness, or usefulness of any information, apparatus, product, or process disclosed, or represents that its use would not infringe privately owned rights. Reference herein to any specific commercial product, process, or service by trade name, trademark, manufacturer, or otherwise does not necessarily constitute or imply its endorsement, recommendation, or favoring by the United States Government or any agency thereof. The views and opinions of authors expressed herein do not necessarily state or reflect those of the United States Government or any agency thereof. 
This report has been reproduced from the best available copy. Available in paper copy and microfiche.

Number of pages in this report: 40

DOE and DOE contractors can obtain copies of this report from:

Office of Scientific and Technical Information

P.O. Box 62

Oak Ridge, TN 37831

(615) 576-8401

This report is publicly available from:

National Technical Information Service

Department of Commerce

5285 Port Royal Road

Springfield, VA 22161

(703) $487-4650$ 


\section{DISCLAIMER}

Portions of this document may be illegible in electronic image products. Images are produced from the best available original document. 
REV. 0

\title{
UMTRA GROUND WATER SAMPLING TECHNIQUES: COMPARISON OF THE TRADITIONAL AND LOW FLOW METHODS
}

July 1995

\author{
Prepared for \\ U.S. Department of Energy \\ Environmental Restoration Division \\ UMTRA Project Team \\ Albuquerque, New Mexico \\ Prepared by \\ Jacobs Engineering Group Inc. \\ Albuquerque, New Mexico
}


TABLE OF CONTENTS

Section

Page

1.0 INTRODUCTION

2.0 POTENTIAL IMPACTS OF LOW FLOW CONVERSION ON THE

UMTRA PROJECT

3.0 LITERATURE REVIEW

3.1 The Kearl papers

3.1.1 Scope of the Kearl studies

3.1.2 Value and limitations of the Kearl study results for the UMTRA Project.

3.2 Shanklin's study at the Fernald, Ohio, site ................................... 3-6

3.2.1 Scope of the Fernald study ............................................. 3-6

3.2.2 Value and limitations of the Fernald study results for the

UMTRA Project .......................................................... $3-8$

3.3 Hurley's study at the Yaworski Lagoon site, Canterbury, Connecticut ...... 3-10

3.3.1 Scope of the Canterbury study.......................................... 3-10

3.3.2 Value and limitations of the Canterbury study results for the UMTRA Project

3.4 U.S. Environmental Protection Agency ground water

sampling - a workshop summary, EPA/600/R-94/205 ...................... 3-14

3.5 Summary of the literature conclusions ....................................... 3-14

4.0 EVALUATION OF THE UMTRA PROJECT LOW FLOW SAMPLING DATA ......... $4-1$

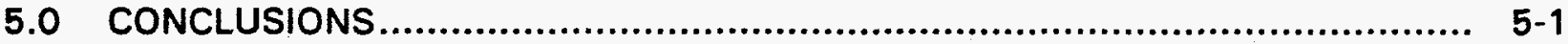

5.1 Options .......................................................................... $5-2$

5.2 Recommendations ................................................................... 5

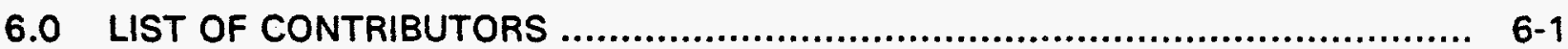

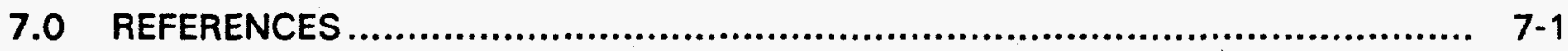




\section{LIST OF FIGURES}

Fiqure

Page

2.1 Possible changes in water quality measurements................................ 2-2

2.2 Low flow sampling effect on natural flushing remediation time .................... $2-4$

\section{LIST OF TABLES}

Table

Page

3.1 Sample mean difference between measured concentrations in paired samples taken by MBV and LF sampling ............................................ 3-5

3.2 Well and purge specifications ...................................................... $3-7$

3.3 Comparison of water quality results of samples collected by low flow and three-bore volume methods at the Fernald Environmental Management Project .

3.4 Low flow and bailer sampling comparison $(\mu \mathrm{g} / \mathrm{L})$

3.5 Low flow and bailer sampling comparison of chromium $(\mu \mathrm{g} / \mathrm{L}$ ).

4.1 Results of suspected anomalies program for low flow and multiple bore volume wells, sampled at three UMTRA Project sites. 


\section{LIST OF ACRONYMS}

\section{Acronym Definition}

$\begin{array}{ll}\text { ANOVA } & \text { analysis of variance } \\ \text { DOE } & \text { U.S. Department of Energy } \\ \text { EPA } & \text { U.S. Environmental Protection Agency } \\ \text { LF } & \text { low flow } \\ \text { MCL } & \text { maximum concentration limit } \\ \text { MBV } & \text { multiple bore volume } \\ \text { NPL } & \text { National Priorities List } \\ \text { POC } & \text { point of compliance } \\ \text { OA } & \text { quality assurance } \\ \text { SOP } & \text { standard operating procedure } \\ \text { SPEAR } & \text { Software Program for Environmental Analysis and Reporting } \\ \text { TAC } & \text { Technical Assistance Contractor } \\ \text { TDS } & \text { total dissolved solids } \\ \text { UMTRA } & \text { Uranium Mill Tailings Remedial Action }\end{array}$




\subsection{INTRODUCTION}

In 1994, the U.S. Department of Energy (DOE) Uranium Mill Tailings Remedial Action (UMTRA) Project initiated a program to convert ground water sampling of monitor wells from the traditional multiple bore volume (MBV) purge and sample method to a new method called low flow (LF) sampling. Bladder pumps were permanently installed in 22 monitor wells at 3 UMTRA Project sites: Durango (Bodo Canyon), Colorado; Monument Valley, Arizona; and Green River, Utah. Fifteen of these wells were sampled for the first time by the LF method in late 1994 and early 1995.

The UMTRA Project LF conversion program was begun in response to the scientific evidence, the U.S. Environmental Protection Agency (EPA) mandate, and the economic incentives favoring LF sampling. Chemical analysis measurements from LF samples will be added to the Project's extensive data base of measurements from samples obtained by MBV and other sampling methods for more than a decade. This data base supports decisions concerning contaminant migration, human and environmental risk, remediation techniques, long-term monitoring at disposal cells, and other issues at UMTRA Project sites.

Recognizing the importance of water quality data to the Project and that little is known about the impact of LF sampling on water quality results, the Technical Assistance Contractor (TAC) proposed that the DOE conduct a Project-specific comparison of chemical analysis data from samples obtained using the MBV and LF sampling methods. In response, the DOE commissioned this report to review the current literature on the subject. With this additional information, the DOE and the TAC will be in a better position to determine the need for and value of a Project-specific comparison study.

The MBV purge and sampling method traditionally employed on the UMTRA Project uses a portable pump positioned above the well screen interval to purge a minimum of one well bore volume (but preferably three to five well bore volumes) from the well before sampling. The pumping rate may be 4 liters $(L)$ per minute or more. The purpose of the MBV purge is to remove stagnant water from the well casing so that the sample water is representative of the water in the aquifer. This and similar purge and sample methods are described in the hydrogeologic literature (Fenn et al., 1977; Gibb et al., 1981; Schuller et al., 1981; EPA, 1986). The Albuquerque Operations Manual standard operating procedure (SOP) 16.2.1.7.3, Sample Collection, Preservation, and Shipment of Water Samples, gives the following directive: "Whenever there is sufficient well water, pump water from the well and purge at least three (3) well volumes" (JEG, n.d.).

LF sampling (also referred to as "micropurging" or "millipurging") is a relatively new sampling method that is increasingly being adopted in the environmental industry. LF sampling consists of sampling a monitoring well at a low discharge rate with a pump located within the screened interval. LF sampling rates, generally 0.1 to $0.5 \mathrm{~L}$ per minute, are lower than the recharge rate of the well to prevent mixing of stagnant casing water with aquifer water in the screened interval. LF sampling is conducted with dedicated 
pumps or dedicated drop tubes (where the depth to the screened interval is within the suction limit), which are permanently installed at a fixed depth in the well, rather than portable pumps, which are inserted and removed before and after the sampling event. The LF purge consists of evacuating the water that stands in the dedicated pump and in the pump discharge line rather than the stagnant water in the well casing. The LF sampling approach assumes that ground water flow through the screened interval is horizontal, laminar, and representative of aquifer water. Moreover, it assumes that there is little interaction between the water flowing through the screened interval and the stagnant water present in the well casing above the screen (Kearl et al., 1992; Robin and Gillham, 1987; Powell and Puls, 1993).

Recent scientific literature indicates that samples collected by the LF method are more representative of aquifer water than samples collected using the traditional MBV purge and sample method. Purging and sampling a well at a low rate is believed to introduce less oxygen and turbidity into the sample. Turbidity is further reduced by the use of dedicated pumps. Unlike portable pumps, which can increase ground water turbidity as they are lowered into the well, dedicated pumps are stationary within the well and cause no disturbance or mixing of the stagnant water column with the screened interval water. Down-hole video studies confirm that fewer particulates or colloids are present in the water column when the pumping equipment is dedicated to the well (Kearl et al., 1992). Thus, LF sampling with dedicated pumps provides a combination of low stress on the aquifer and no mixing of the water column in the well, resulting in the most representative sample available with current sampling technology. The U.S. Environmental Protection Agency (EPA) recognizes the LF method as "providing a higher quality sample that more closely represents the mobile dissolved and colloidal components in the formation" and "this is the direction in which the state of professional practice must proceed." (EPA, 1993a).

The LF sampling method with dedicated equipment has several additional advantages over the traditional sampling methods.

- Dedicated pumps eliminate the potential for cross contamination between wells because the pump is used in only one well.

- The use of dedicated equipment permits a high degree of control over the purge volume and flow rate for a well, which can be expected to reduce the variation in water quality data between sampling events.

- LF sampling can be significantly faster and produces less purge water than sampling by the traditional MBV method.

- Where all wells to be sampled on a site are outfitted with dedicated pumps, the need for an equipment blank quality assurance (OA) sample and analysis is eliminated. 
- The economic benefits of LF sampling, including reduced labor and chemical analysis costs, may be sufficient to recover the equipment and installation costs of dedicated equipment after only a few sampling rounds.

With respect to potential changes in water quality results that may occur from conversion to LF sampling, the following questions are important to the UMTRA Project:

- How different are water quality results between MBV and LF samples?

- Are the differences predictable?

- Are certain constituents affected more than others?

- Does the hydrogeologic environment impact the differences in analytical results?

This report describes the potential changes in water quality data that may occur with the conversion from MBV to LF sampling and provides two examples of how such a change might impact Project decisions. The existing scientific literature on LF sampling is reviewed and the new LF data from three UMTRA Project sites are evaluated seeking answers to the questions posed above. Several possible approaches that the UMTRA Project may take to address issues unanswered by the literature are presented and compared, and a recommendation is offered for the future direction of the LF conversion effort. 


\subsection{POTENTIAL IMPACTS OF LOW FLOW CONVERSION ON THE UMTRA PROJECT}

The potential impacts of conversion from MBV to LF sampling method on UMTRA Project data are illustrated in terms of five possible outcomes. These are presented as generic type curves in Figure 2.1.

- Figure 2.1A shows no change in the constituent concentration behavior after conversion from MBV to LF sampling.

- Figure 2.1B shows a shift up for the constituent concentrations but no change in variability of the data.

- Figure 2.1C shows a shift down for the constituent concentrations with no change in variability.

- Figure 2.1D shows no shift upward or downward in constituent concentrations but an increase in the range of variability of the results.

- Figure 2.1E shows no shift in the constituent concentrations but a decrease in the variability of the data.

The results shown in Figure 2.1A would have no impact on the UMTRA Project. Results in 2.1B and 2.1C could have an impact on the Project. However, data could be interpreted correctly if Project technical staff were aware of the reasons for the shift (e.g., a change in sampling method rather than a change in ground water quality). Results in 2.1D could have an adverse impact on the Project, making data interpretation and policy decisions based on the data more difficult. Results in 2.1E would make these interpretations and decisions easier due to less variability in the data. It is also possible that a combination of a shift and a change in data variability could occur simultaneously.

The UMTRA Project conducts both inter-well and intra-well comparisons of ground water quality data. Inter-well comparisons evaluate differences between wells during the same time period (e.g., background compared to on-site), whereas intra-well comparisons evaluate differences in the same well during different time periods (e.g., before compared to after remediation). Both types of comparisons could be affected by conversion to LF sampling if that conversion introduced a sudden change in water quality measurements.

A specific example of an inter-well comparison occurs at Rifle, Colorado, where private wells in the area have been monitored by the Project to assess possible impacts associated with the Rifle processing sites. To date, the uranium concentrations measured in private wells have fallen within the range of DOE monitor well background levels. If the DOE monitor wells were converted to LF sampling (with no corresponding conversion of the method of sampling the private wells) and if LF sampling results indicated a downward shift in uranium concentrations in background ground water samples (Figure $2.1 \mathrm{C}$ ), then 
Figure 2.1

Possible Changes in Water Quality Measurements
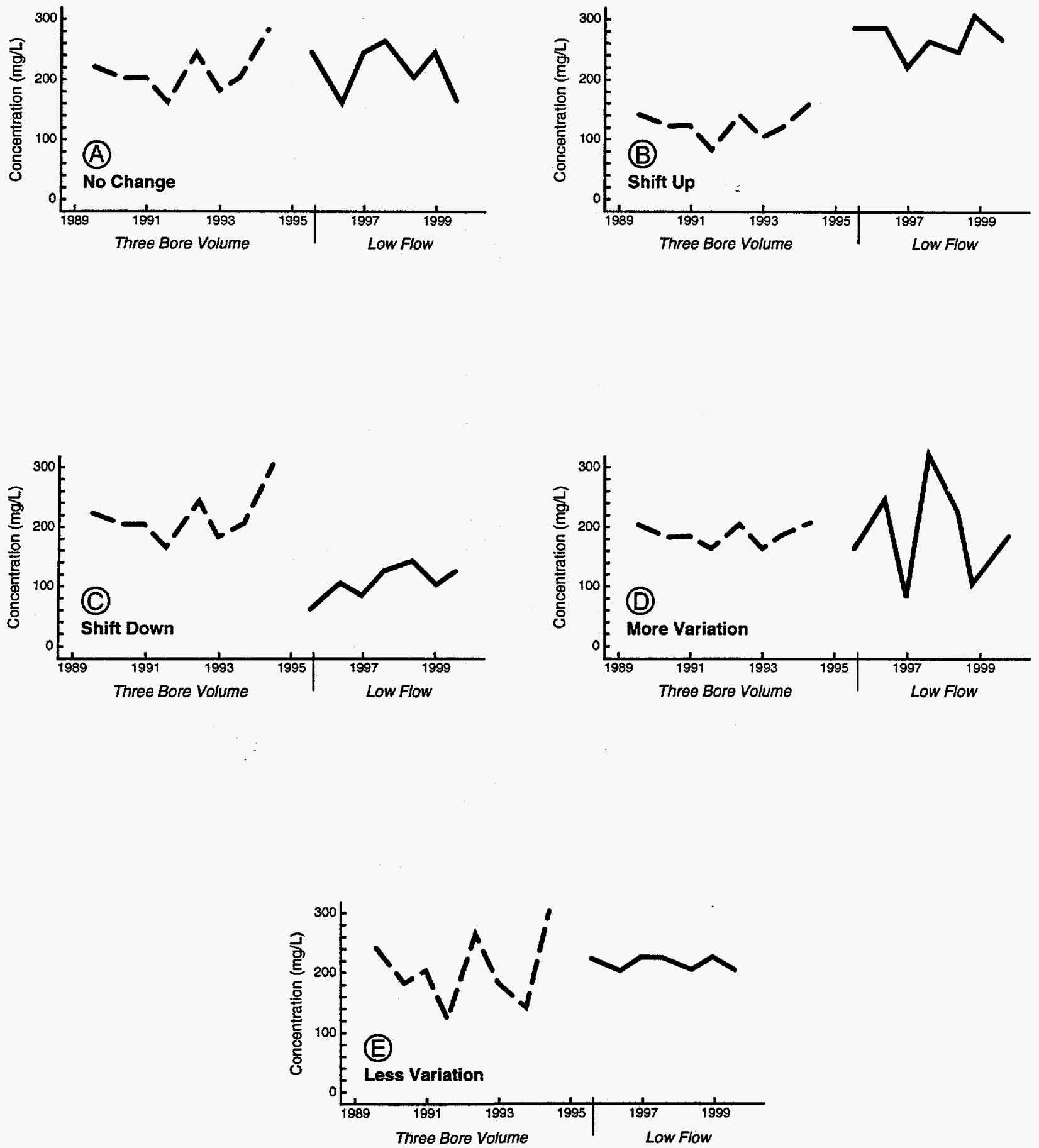
the uranium levels in the private wells might exceed background and be mistakenly attributed to plume migration. If this scenario occurs, the DOE might be required to demonstrate that the apparent elevation of uranium concentrations in private wells over background monitor wells is an artifact of differences in the method of obtaining water samples from the two types of wells.

Evaluation of time trends in concentration levels is an example of an intra-well comparison that could potentially be affected by a change in water quality sampling results associated with conversion from MBV to LF sampling. Trends in water quality measurements over time will be used on the UMTRA Project to defend and gauge the ground water remediation strategy at processing sites. If, for example, wells at the Riverton, Wyoming, site were converted to the LF sampling technique, a possible shift in contaminant concentration could affect model estimates of the time required for natural flushing to remediate site ground water. In Figure 2.2, Curve A shows the effect of natural flushing on the concentration of a hypothetical contaminant over time, as measured by samples obtained by the traditional MBV sampling method. Time for natural flushing to occur is represented by the intersection of the time trend with a cleanup standard, depicted on Figure 2.2 as a maximum concentration limit (MCL). Curve B of Figure 2.2 represents the hypothetical time-concentration trend for the same well based on contaminant concentrations in samples obtained by LF sampling, under the assumption that LF sampling results in a downward shift in contaminant levels by an amount $\Delta_{1}$. As a result of the $\Delta_{1}$ shift, Curve $B$ reaches the cleanup standard after a shorter period of time $\left(\Delta_{2}\right)$ than does Curve A. Thus, conversion to LF sampling could conceivably save years of ground water sampling and analysis labor and expense and bring the site to closure sooner than projected based on traditional sampling analyses. 


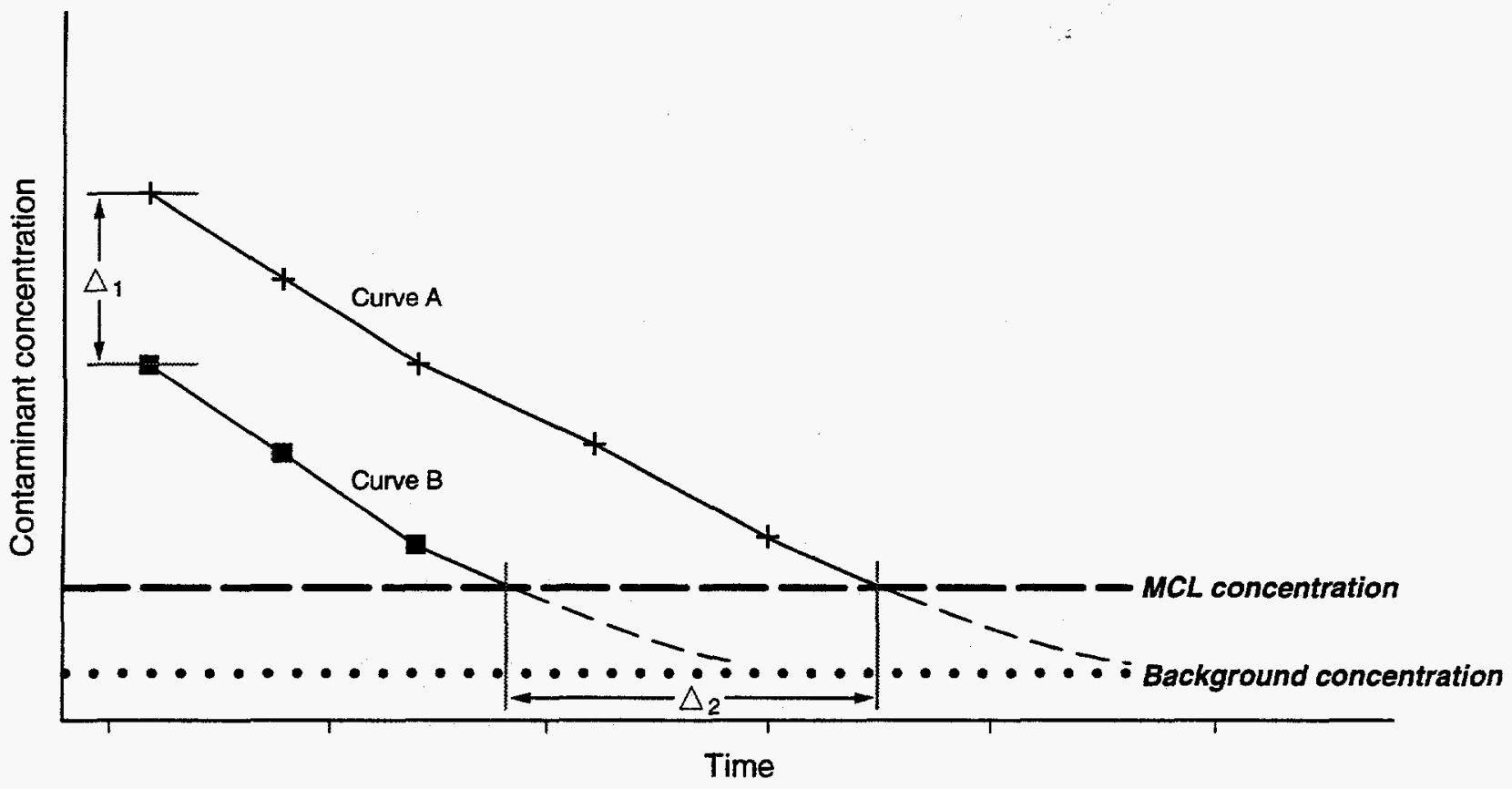

Legend

$+\quad$ Multiple bore volume sampling

Low flow sampling 


\subsection{LITERATURE REVIEW}

Whether either of the scenarios presented in Section 2.0 could actually occur depends on the significance of the analytical differences between samples obtained by MBV and LF sampling methods. In this section, the scientific literature is reviewed to address the question of differences between MBV and LF sampling results. The following studies represent the current state of knowledge on this subject:

- Field Comparison of Micropurging vs. Traditional Ground Water Sampling (Kearl et al., 1993).

- Field Comparison of Micropurging vs. Traditional Ground Water Sampling (Kearl et al., 1994).

- "Suggested Modifications to Ground Water Sampling Procedures Based on Observations From the Colloidal Borescope" (Kearl et al., 1992).

- Waste Minimization and Groundwater Sampling Efficiency: A New Technique for Purging Groundwater Monitoring Wells at the Fernald Environmental Management Project (Shanklin, 1993).

- ACL Monitoring Using a Low-flow Sampling Technique, A Case Study Hurley and Whitehouse, 1995).

- "A Study of the Impact of Monitoring Well Purging and Filtering Techniques on Metals Concentrations in Groundwater Samples from the Auburn Road Landfill Site in Londonderry, N. H." (EPA, 1993b).

- "You Can't Always Get What You Want But You Can Get What You Need" (EPA, 1993c).

\subsection{THE KEARL PAPERS}

In a paper written in 1993 (Kearl et al., 1993) and in a nearly identical paper written in 1994 (Kearl et al., 1994), Kearl and Korte compared ground water samples using the MBV methods and the LF method. The 1993 version of the paper is more detailed and discusses a Kansas City, Missouri, site, while the 1994 version appears to target a more general readership and discusses the same Kansas City site and a site in Kentucky. 


\subsubsection{Scope of the Kearl studies}

\section{Kansas City site}

At the Kansas City site, three wells contaminated with chlorinated solvents were sampled by the LF method, then sampled by the MBV method. This procedure was repeated at one-week intervals until four sampling events had been completed. Several months later, the same procedure was repeated, resulting in a total of eight concurrent pairs of water samples for each well. The water samples were analyzed for nine inorganic constituents (aluminum, arsenic, barium, calcium, iron, magnesium, manganese, sodium, and zinc) and two organics (1,2-dichoroethene and vinyl chloride).

Comparison of the unfiltered water sample data from the two sampling methods indicates that for most analytes, the median difference in analytical results is near zero, suggesting that there is no systematic difference in the values measured by the two methods. However, this conclusion is dependent on the statistical method used to evaluate the data.

In the 1993 paper, the authors compared the eight concurrent pairs of analytical results for each well and constituent using a paired t-test. Of the 27 statistical tests for inorganics ( 9 constituents times 3 wells), 12 test results showed statistically significant differences between the sampling methods: barium and iron in all 3 wells; magnesium in 2 of the 3 wells; and aluminum, calcium, manganese, and zinc in 1 well each. None of the statistical tests for organics were significant at the 0.05 level of significance. The authors reviewed the cases of significant results and determined that the observed differences were generally small from a practical standpoint. They also emphasized that the hydrogeologic conditions at the site, the low hydraulic conductivity, the clayey aquifer, and a reducing subsurface environment may have affected sampling results for redox-sensitive analytes.

In the 1994 paper, the authors reevaluated the data using the nonparametric sign test. With this method, only 5 of the 27 inorganic results were significant at the 0.05 level of significance. All five significant results occurred in the same well, and in each case the LF results were higher than the MBV results. An isolated significant difference for vinyl chloride also occurred. The authors concluded that their results "justify more extensive study in order to provide a substantial data set for conclusive statistical analysis." (Kearl et al., 1994)

\section{Paducah site}

At the Paducah, Kentucky, site, three wells were sampled using the LF method once per day for three consecutive days to assess the repeatability of LF sampling. Samples were analyzed for 17 inorganic and 3 organic constituents. Review of the analytical results shows only minor differences between LF sampling events. The limited data set does not allow a rigorous statistical analysis, and it is recognized 
that a "much larger data set is necessary to provide unequivocal statistical significance." (Kearl et al., 1994).

\subsubsection{Value and limitations of the Kearl study results for the UMTRA Project}

\section{Kansas City}

The study design of taking water samples on the same day using both sampling methods is optimal for detecting shifts in water quality (Figures 2.1B and 2.1C) that are specifically attributable to sampling method. With this design, the eight sampling events at the Kansas City site might be expected to produce reasonably precise estimates of the average difference between the methods, provided the data from the different events are independent. However, the weekly sampling interval used in the study may have been too short to produce independent data, especially considering the low permeability of the aquifer system at the site. If the data from the weekly sampling events were in fact positively correlated, then the statistical significance reported in the papers may be overstated.

Another statistical issue limits interpretation of the Kearl results. The 1993 paired t-test comparison found several more cases of statistically significant results among the inorganics than were detected using the 1994 sign test. This may be explained by the fact that the t-test almost always has greater statistical power than the sign test. However, it cannot automatically be assumed that the $1993 \mathrm{t}$-test results are correct because the validity of the t-test relies on the assumption of normally distributed data. The reevaluation of the data in 1994 may have been prompted by the realization that this assumption was untenable. However, if this were the case, several better options were available to the authors than the sign test, which is very insensitive. It is not clear, therefore, whether the Kearl data yielded several statistically significant results or just a few.

Because the article did not provide explicit information on the concentration levels of the various constituents in the ground water at the test site, the reader cannot evaluate the magnitude of the observed differences between the LF and MBV results. Also, the article did not address the possibility of differences in data variability produced by the two sampling methods (Figures 2.1D and 2.1E).

The limitations could be resolved if the original data from the Kearl study could be obtained and reanalyzed by TAC statisticians and geochemists. However, it remains questionable whether the hydrologic or geochemical conditions at the Kansas City test site are comparable to any of the UMTRA sites. The ground water at the test site existed under very reducing conditions. Ground water at the UMTRA sites exists under oxidizing or reducing conditions, depending on the site. Contamination at the test site was limited to organic compounds, so the concentration levels of inorganic constituents evaluated at the test site may not approximate the levels at UMTRA sites. The differences presented in the Kearl study were based on unfiltered water samples; some of these differences may be 
reduced by filtration, a practice generally employed at UMTRA Project sites. Lastly, the inorganics of particular concern for the UMTRA Project (nitrate, uranium, molybdenum, selenium, and vanadium) were not included in the Kearl studies.

Notwithstanding these limitations, the Kearl papers yield some interesting hypotheses of value to the UMTRA Project. The sample mean difference for each well and constituent in the study can be inferred from the upper and lower confidence intervals reported in the 1993 paper (Table 3.1) (Kearl et al., 1993). Wells 2 and 3 are screened deep in the aquifer, whereas well 1 is screened at the water table. Kearl defined this difference as MBV minus LF, so that a negative difference occurs if LF results were higher than MBV.

Table 3.1 shows that the sample mean zinc results were lower in LF than in MBV samples for all 3 wells. The authors attribute these results to reduced turbidity of LF water samples. If this generally is true, then LF samples typically would contain lower concentrations of most metals. However, the two deeper wells show significantly higher concentrations of iron in the LF samples than in the MBV samples. The authors hypothesize that oxygen introduced during the MBV purging may cause iron to precipitate. This phenomenon could offset or even reverse the effects of greater turbidity in MBV samples for redox-sensitive constituents such as iron and manganese, as well as for anions and cations that tend to adhere to iron or iron colloids. The net effect of these opposite tendencies may vary from well to well, and possibly even from sample to sample drawn from the same well. However, the potential for this type of problematic variability is predictable to the extent that soluble iron is present in the ground water. The results shown in Table 3.1 suggest the possibility that the differences in concentration levels measured in MBV and LF samples are great enough to alter risk calculations associated with potential exposures to the ground water by people, plants, and animals. In well 2, the average iron concentration in LF samples was almost $40 \mathrm{mg} / \mathrm{L}$ higher than in MBV samples. In the same well, the average manganese in LF samples was almost $8 \mathrm{mg} / \mathrm{L}$ higher than in MBV samples. Arsenic concentrations were higher in LF samples for well 3 by an average of $0.17 \mathrm{mg} / \mathrm{L}$, although this last result did not reach statistical significance.

\section{Paducah site}

The Paducah study was designed to evaluate the repeatability of analytical measurements from samples collected by LF sampling. Samples were collected on three consecutive days from three wells. All samples were split and analyzed by two independent laboratories. Unfortunately, the authors combined the analytical results from the two laboratories and the three wells into a single daily average for reporting and analysis. The small variation among the three daily averages is not surprising, because averaging tends to smooth out the individual variations in water quality measurements. In addition, evaluation of the Paducah data is limited 
Table 3.1 Sample mean difference between measured concentrations in paired samples taken by MBV and LF sampling

\begin{tabular}{|c|c|c|c|c|}
\hline Chemical & Well & $\begin{array}{c}\begin{array}{c}\text { Lower } \\
\text { confidence } \\
\text { limit }\end{array} \\
\end{array}$ & $\begin{array}{c}\begin{array}{c}\text { Upper } \\
\text { confidence } \\
\text { limit }\end{array} \\
\end{array}$ & $\begin{array}{c}\text { Sample } \\
\text { mean difference } \\
\text { (MBV-LF) } \\
\end{array}$ \\
\hline $\begin{array}{l}\text { Aluminum } \\
\nwarrow\end{array}$ & $\begin{array}{l}1 \\
2 \\
3\end{array}$ & $\begin{array}{r}0.754 \\
-0.258 \\
-0.098\end{array}$ & $\begin{array}{l}8.414 \\
0.133 \\
0.168\end{array}$ & $\begin{array}{r}4.584 \\
-0.063 \\
0.035\end{array}$ \\
\hline Arsenic & $\begin{array}{l}1 \\
2 \\
3\end{array}$ & $\begin{array}{l}-0.021 \\
-0.023 \\
-0.353\end{array}$ & $\begin{array}{l}0.040 \\
0.005 \\
0.012\end{array}$ & $\begin{array}{r}0.010 \\
-0.009 \\
-0.171\end{array}$ \\
\hline Barium & $\begin{array}{l}1 \\
2 \\
3\end{array}$ & $\begin{array}{r}0.009 \\
-0.763 \\
-0.14\end{array}$ & $\begin{array}{r}0.249 \\
-0.387 \\
-0.003\end{array}$ & $\begin{array}{r}0.129 \\
-0.575 \\
-0.07\end{array}$ \\
\hline Calcium & $\begin{array}{l}1 \\
2 \\
3\end{array}$ & $\begin{array}{r}-27.02 \\
-69.24 \\
-4.20\end{array}$ & $\begin{array}{r}18.02 \\
-21.00 \\
0.30\end{array}$ & $\begin{array}{r}-4.50 \\
-45.12 \\
-1.95\end{array}$ \\
\hline Iron & $\begin{array}{l}1 \\
2 \\
3\end{array}$ & $\begin{array}{r}3.77 \\
-48.2 \\
-8.12\end{array}$ & $\begin{array}{r}16.27 \\
-27.66 \\
-0.36\end{array}$ & $\begin{array}{l}10.02 \\
-37.9 \\
-4.24\end{array}$ \\
\hline Magnesium & $\begin{array}{l}1 \\
2 \\
3\end{array}$ & $\begin{array}{r}-5.37 \\
-11.61 \\
-0.44\end{array}$ & $\begin{array}{r}2.87 \\
-6.25 \\
-0.036\end{array}$ & $\begin{array}{l}-1.25 \\
-8.93 \\
-0.24\end{array}$ \\
\hline Manganese & $\begin{array}{l}1 \\
2 \\
3\end{array}$ & $\begin{array}{l}-2.287 \\
-10.61 \\
-0.242\end{array}$ & $\begin{array}{l}1.153 \\
-4.94 \\
0.006\end{array}$ & $\begin{array}{r}-0.567 \\
-7.78 \\
-0.118\end{array}$ \\
\hline Sodium & $\begin{array}{l}1 \\
2 \\
3\end{array}$ & $\begin{array}{r}-1.92 \\
-17.07 \\
-1.37\end{array}$ & $\begin{array}{l}1.05 \\
6.04 \\
0.80\end{array}$ & $\begin{array}{l}-0.44 \\
-5.52 \\
-0.29\end{array}$ \\
\hline Zinc & $\begin{array}{l}1 \\
2 \\
3 \\
\end{array}$ & $\begin{array}{r}0.032 \\
-0.004 \\
0.000 \\
\end{array}$ & $\begin{array}{l}0.074 \\
0.036 \\
0.023 \\
\end{array}$ & $\begin{array}{l}0.053 \\
0.016 \\
0.012 \\
\end{array}$ \\
\hline
\end{tabular}

Notes: From Kearl et al. (1993).

Results shown in milligrams per liter (mg/L). 
because there are no repetitive MBV sampling methods with which to compare the LF results.

\subsection{SHANKLIN'S STUDY AT THE FERNALD, OHIO, SITE}

A paper entitled Waste Minimization and Groundwater Sampling Efficiency: A New Technique for Purging Groundwater Monitoring Wells at the Fernald Environmental Management Project, prepared by Dean Shanklin, Fernald Environmental Restoration Management Corporation, Cincinnati, Ohio, presents the methods and results of a comparison study of LF sampling and MBV sampling from monitoring wells at the Fernald, Ohio, site (Shanklin, 1993). The paper was prepared for the Cincinnati office of the DOE under contract DE-AC05-860R2160.

\subsubsection{Scope of the Fernald study}

The stated purpose of the LF/MBV comparison at Fernald was to "demonstrate that waste generation can be minimized and ground water sampling efficiency and quality can be improved." The paper cites EPA guidance and recent scientific literature that recommend adopting the most efficient sampling method based on local hydrological conditions. This allows the site owner/operator to select a sampling method from among many options. For the Fernald site, LF sampling was an option that provided high quality data while minimizing the amount of contaminated purge water brought to the surface. The study was designed to show that there was no reduction in sample quality and that there were significant economic benefits from converting to the LF method.

The study consisted of sampling four wells, four times, by the following three methods: 1) LF sampling with a dedicated pump after a purge of two times the volume of the pump plus the volume of the standing water in the discharge line, 2) a one-bore volume (BV) purge followed by sampling, and 3) a three-bore volume (3BV) purge followed by sampling. The sampling events were conducted every 4 days over a 13-day period. The purge rate was $0.5 \mathrm{~L}$ per minute for the $L F$ method and 2 to $3 \mathrm{~L}$ per minute for the traditional purge methods. The discharge rate was reduced to between 0.1 and $0.2 \mathrm{~L}$ per minute for all sampling.

Field parameters of $\mathrm{pH}$, temperature, specific conductivity, and dissolved oxygen were measured during each sampling event, but sampling was not contingent on parameter stabilization. The samples were analyzed for calcium, iron, magnesium, fluoride, total dissolved solids (TDS), and alkalinity in filtered samples; and calcium, iron, magnesium, phosphate, and uranium in unfiltered samples. Table 3.2 presents well and purge specifications used in the study. 
Table 3.2 Well and purge specifications

\begin{tabular}{ccccccccc}
\hline & $\begin{array}{c}\text { Total } \\
\text { depth } \\
\text { (ft) }\end{array}$ & $\begin{array}{c}\text { Bore } \\
\text { inside } \\
\text { diameter } \\
\text { (inches) }\end{array}$ & $\begin{array}{c}\text { Depth } \\
\text { to } \\
\text { water } \\
(\mathrm{ft})\end{array}$ & $\begin{array}{c}\text { Screen } \\
\text { length } \\
(\mathrm{ft})\end{array}$ & $\begin{array}{c}\text { Top of } \\
\text { screen } \\
(\mathrm{ft})\end{array}$ & $\begin{array}{c}\text { Slot size } \\
\text { (inch) }\end{array}$ & $\begin{array}{c}\text { Pump plus } \\
\text { Install date }\end{array}$ & $\begin{array}{c}\text { tubing } \\
\text { volume (L) }\end{array}$ \\
\hline 2106 & 31.9 & 4 & 17.3 & 15 & 13.1 & 0.010 & $01 / 31 / 89$ & 2.7 \\
2391 & 25.1 & 4 & 12.4 & 15 & 8.4 & 0.010 & $03 / 05 / 90$ & 2.7 \\
3106 & 89.1 & 4 & 17.7 & 10 & 77.1 & 0.010 & $01 / 18 / 89$ & 7.5 \\
3391 & 74.7 & 4 & 12.2 & 10 & 63.0 & 0.010 & $05 / 15 / 90$ & 6.5 \\
\hline
\end{tabular}

From: Shanklin, 1993.

Waste minimization and cost reduction

During a typical 3-month monitoring period at Fernald, 90 to 110 monitoring wells are sampled and over 7000 gallons of purge water are generated by traditional sampling methods. Prior to chemical analysis, the water must be assumed hazardous and must be carefully handled, stored, and treated pending appropriate disposal. These procedures are time-consuming and potentially dangerous to personnel.

A considerable cost reduction was expected at Fernald as a result of converting to the LF sampling method. As stated in the paper, using dedicated pumps in the wells eliminates the need for equipment rinsate samples since decontamination of portable sampling equipment is not needed. Further, additional money is saved by significantly reducing the storage and handling of large volumes of purge water. Finally, since LF sampling is faster than MBV sampling for most of the wells, the sampling efficiency is improved. The estimated annual cost reduction at Fernald as a result of the LF sampling conversion is $\$ 115,000$. Based on a personal conversation between the UMTRA Project water sampling program manager and Dean Shanklin, author of the Fernald study, these savings have actually occurred (Shanklin, 1995).

\section{Statistical analysis}

The laboratory data were evaluated to determine if the different sampling methods have statistically distinguishable effects on water quality measurements. Three different statistical methods were presented in the paper. A two-way analysis of variance (ANOVA) test was first performed for each constituent, with the two factors being sampling method and wells. This statistical method allows that the wells may differ in water quality and that the impact of the sampling method on water quality may differ from one well to another. However, the method assumes that there are no systematic differences between the four samplings and that the 
temporal variability in concentrations follows a normal distribution with equal variability in all wells and for all sampling methods.

Provided the underlying assumptions are valid, the two-way ANOVA is the optimal test for evaluating differences between the sampling methods. If the assumptions are untrue, however, the method may produce invalid results or may have reduced power to detect these differences. For this reason, the authors conducted two additional types of analyses that rely on a weaker set of assumptions. A one-way ANOVA test and the nonparametric Kruskal-Wallis test were conducted separately for each well and constituent. These tests eliminate the required assumption of equal variability in data from the four wells, and the Kruskal-Wallis test also eliminates the need for the assumption of normality. These tests continue to rely on the assumption that there are no systematic differences in the data from the four sampling rounds and that the different sampling methods produce equal variability in data.

Only one case of a statistically significant difference in concentration levels associated with the sampling method was identified. That case was for alkalinity levels in well 2106, based on the one-way ANOVA test. For that well, alkalinity is in the range of 250 to $300 \mathrm{mg} / \mathrm{L}$, and the LF sample data were approximately 6 percent lower than data from 3BV sampling. The authors believe this 1 case of significance out of 40 individual statistical tests may represent a false positive result.

\subsubsection{Value and limitations of the Fernald study results for the UMTRA Project}

The Fernald study is extremely valuable to the Project because the raw data from the study were included in the report. Table 3.3 summarizes the concentration levels measured in LF and 3BV samples and the percent difference between concentrations measured in pairs of LF and 3BV samples from the same sampling round. These data show that the Fernald study wells are relatively "clean" by UMTRA Project standards. The observable differences between the LF and 3BV data are small and, with the exception of iron, do not follow a consistent pattern for the wells.

Iron concentrations measured in unfiltered samples taken by LF are consistently higher than those taken using the 3BV sampling method. This same phenomenon was found in the Kearl study and was discussed earlier. It is notable that filtering the samples prior to chemical analysis reduces the observable differences between LF and 3BV iron levels at the same time that it reduces the measured iron levels.

The Fernald study provides the first known comparison of uranium concentrations from LF and 3BV samples. Unfortunately, three of the four wells contain essentially no uranium at all (concentrations generally less than $0.001 \mathrm{mg} / \mathrm{L}$ ). Differences between the sampling methods at such low levels are not of particular concern to the UMTRA Project. The fourth well, 2106, has uranium concentrations slightly 
Table 3.3 Comparison of water quality results of samples collected by low flow and three-bore volume methods at the Fernald Environmental Management Project

\begin{tabular}{|c|c|c|c|c|c|}
\hline \multirow[b]{2}{*}{ Constituent } & \multirow[b]{2}{*}{ Method } & \multicolumn{4}{|c|}{ Well Identifier } \\
\hline & & 2106 & 3106 & 3391 & 2391 \\
\hline Alkalinity & $\begin{array}{l}\text { LF } \\
\text { 3BV } \\
\% \text { Diff. }\end{array}$ & $\begin{array}{c}256 \pm 3 \\
275 \pm 10 \\
-6.6 \pm 2.9\end{array}$ & $\begin{array}{c}252 \pm 3 \\
255 \pm 2 \\
-1.2 \pm 1.0\end{array}$ & $\begin{array}{l}273 \pm 9 \\
270 \pm 13 \\
1.1 \pm 3.3\end{array}$ & $\begin{array}{r}280 \pm 12 \\
286 \pm 15 \\
-2.1 \pm 3.3\end{array}$ \\
\hline $\begin{array}{l}\text { Calcium } \\
\text { (filtered) }\end{array}$ & $\begin{array}{l}\text { LF } \\
3 B V \\
\% \text { Diff. }\end{array}$ & $\begin{aligned} 93 & \pm 5 \\
93 & \pm 4 \\
-0.9 & \pm 1.6\end{aligned}$ & $\begin{aligned} 92 & \pm 4 \\
92 & \pm 3 \\
-0.2 & \pm 1.6\end{aligned}$ & $\begin{aligned} 96 & \pm 5 \\
97 & \pm 8 \\
-0.3 & \pm 3.4\end{aligned}$ & $\begin{array}{c}100 \pm 2 \\
101 \pm 5 \\
-0.7 \pm 4.1\end{array}$ \\
\hline $\begin{array}{l}\text { Calcium } \\
\text { (unfiltered) }\end{array}$ & $\begin{array}{l}\text { LF } \\
\text { 3BV } \\
\% \text { Diff. }\end{array}$ & $\begin{array}{c}96 \pm 4 \\
96 \pm 3 \\
0.4 \pm 4.9\end{array}$ & $\begin{array}{c}92 \pm 2 \\
91 \pm 3 \\
0.8 \pm 2.3\end{array}$ & $\begin{array}{c}99 \pm 3 \\
97 \pm 4 \\
2.4 \pm 3.0\end{array}$ & $\begin{array}{c}99 \pm 3 \\
104 \pm 6 \\
-4.9 \pm 3.0\end{array}$ \\
\hline $\begin{array}{l}\text { Iron } \\
\text { (filtered) }\end{array}$ & $\begin{array}{l}\text { LF } \\
\text { 3BV } \\
\% \text { Diff. }\end{array}$ & $\begin{array}{c}0.008 \pm 0.004 \\
0.011 \pm 0.010 \\
27 \pm 104\end{array}$ & $\begin{array}{c}0.008 \pm 0.003 \\
0.013 \pm 0.006 \\
-35 \pm 27\end{array}$ & $\begin{array}{l}1.7 \pm 0.4 \\
1.5 \pm 0.7 \\
38 \pm 83\end{array}$ & $\begin{array}{l}0.52 \pm 0.86 \\
0.78 \pm 0.94 \\
684 \pm 1480\end{array}$ \\
\hline $\begin{array}{l}\text { Iron } \\
\text { (unfiltered) }\end{array}$ & $\begin{array}{l}\text { LF } \\
\text { 3BV } \\
\text { \% Diff. }\end{array}$ & $\begin{array}{c}0.52 \pm 0.89 \\
0.10 \pm 0.15 \\
354 \pm 290\end{array}$ & $\begin{aligned} 0.010 & \pm 0.005 \\
0.005 & \pm 0.001 \\
88 & \pm 90\end{aligned}$ & $\begin{aligned} 1.7 & \pm 1.1 \\
1.5 & \pm 1.0 \\
13 & \pm 12\end{aligned}$ & $\begin{aligned} 3.2 & \pm 1.9 \\
1.6 & \pm 1.0 \\
1370 & \pm 2660\end{aligned}$ \\
\hline $\begin{array}{l}\text { Magnesium } \\
\text { (filtered) }\end{array}$ & $\begin{array}{l}\text { LF } \\
\text { 3BV } \\
\% \text { Diff. }\end{array}$ & $\begin{array}{c}23 \pm 1 \\
23 \pm 1 \\
-0.7 \pm 0.8\end{array}$ & $\begin{array}{c}23 \pm 1 \\
23 \pm 1 \\
0.0 \pm 2.4\end{array}$ & $\begin{array}{c}25 \pm 3 \\
25 \pm 3 \\
0.0 \pm 3.1\end{array}$ & $\begin{array}{c}27 \pm 1 \\
27 \pm 2 \\
-0.8 \pm 3.8\end{array}$ \\
\hline $\begin{array}{l}\text { Magnesium } \\
\text { (unfiltered) }\end{array}$ & $\begin{array}{l}\text { LF } \\
\text { 3BV } \\
\% \text { Diff. }\end{array}$ & $\begin{array}{c}24 \pm 1 \\
24 \pm 1 \\
0.5 \pm 4.2\end{array}$ & $\begin{array}{c}23 \pm 1 \\
22 \pm 1 \\
0.9 \pm 2.6\end{array}$ & $\begin{array}{c}25 \pm 2 \\
25 \pm 3 \\
3.0 \pm 3.6\end{array}$ & $\begin{aligned} 27 & \pm 2 \\
28 & \pm 3 \\
-5.6 & \pm 2.6\end{aligned}$ \\
\hline TDS & $\begin{array}{l}\text { LF } \\
\text { 3BV } \\
\% \text { Diff. }\end{array}$ & $\begin{array}{l}370 \pm 69 \\
417 \pm 60 \\
-11 \pm 12\end{array}$ & $\begin{array}{c}469 \pm 33 \\
439 \pm 42 \\
8 \pm 12\end{array}$ & $\begin{array}{c}407 \pm 126 \\
437 \pm 104 \\
-8 \pm 12\end{array}$ & $\begin{array}{c}465 \pm 91 \\
428 \pm 42 \\
8 \pm 14\end{array}$ \\
\hline $\begin{array}{l}\text { Uranium } \\
\text { (unfiltered) }\end{array}$ & $\begin{array}{l}\text { LF } \\
3 B V \\
\% \text { Diff. }\end{array}$ & $\begin{aligned} 0.050 & \pm 0.001 \\
0.051 & \pm 0.002 \\
-2.1 & \pm 3.1\end{aligned}$ & $\begin{aligned} 0.0012 & \pm 0.0001 \\
0.0011 & \pm 0.0001 \\
12 & \pm 10\end{aligned}$ & $\begin{array}{c}0.0004 \pm 0.0004 \\
0.0005 \pm 0.0005 \\
-17 \pm 17\end{array}$ & $\begin{aligned} 0.0007 & \pm 0.0003 \\
0.0009 & \pm 0.0005 \\
-20 & \pm 17\end{aligned}$ \\
\hline
\end{tabular}

3BV - 3-bore volume

LF - low flow

TDS - total dissolved solids

Notes: 1. Study entailed four rounds of sampling of wells using both $L F$ and $3 B V$ methods.

2. Percent difference between $L F$ and $3 B V$ analytical results for a sampling round (\% Diff.) $=$ 100(BV-3BV)/3BV.

3. Reported are the mean \pm the standard deviation of results between sampling rounds. Results are rounded to less accuracy than the original data.

4. Analytical results are presented in $\mathrm{mg} / \mathrm{L}$.

5. Data from Shanklin (1993). 
above the MCL of $0.044 \mathrm{mg} / \mathrm{L}$. Differences between the LF and 3BV data are negligible for this well.

The general conclusion of the Fernald study authors is that water quality will be unaffected and time and money will be saved by transition from 3BV to LF sampling. However, issues associated with iron are unresolved, and the Fernald study contains limited information on the effects of sampling method on other metals. Even though uranium was included in the Fernald study, one cannot conclude that the UMTRA Project will obtain comparable results from Project wells with 100 to 1000 times higher uranium concentrations than those in the Fernald study.

\subsection{HURLEY'S STUDY AT THE YAWORSKI LAGOON SITE, CANTERBURY, CONNECTICUT}

ACL Monitoring Using A Low-flow Sampling Technique, prepared by D. Hurley and J. Whitehouse (1995), covers the methods and findings of sampling by several traditional methods followed by full conversion to LF sampling in nine wells on a Canterbury, Connecticut, site. The conversion resulted in a decrease in results of concentration levels of several monitored parameters. These results, in turn, allowed those parameters to be dropped from the monitoring list.

\subsubsection{Scope of the Canterbury study}

The Canterbury site is located along the Quinebaug River and consists of a lagoon on a 100-acre (40-hectare) parcel. From 1950 to 1973 , the site was used for disposal of approximately 50,000 drums of solvent waste, paint, textile dyes, acids, resins, and other miscellaneous industrial wastes. The primary ground water contaminants are the solvents methylethylketone, methylisobutylketone, tetrahydrofuran, toluene, and xylene. In 1984, the site was placed on the EPA's National Priorities List (NPL) and a record of decision was issued in 1988 that required post-closure compliance ground water monitoring.

The site geology includes Holocene alluvium (approximately 20 feet [ft] thick) overlying Pleistocene stratified glacial drift ( 25 to $45 \mathrm{ft}$ thick) and glacial till deposits ( 0 to $40 \mathrm{ft}$ thick). These sediments are underlain by highly fractured bedrock (gneiss). Monitoring wells on the site are completed in shallow, intermediate, and deep aquifer zones that correspond to the alluvium, drift and till, and bedrock.

Prior to 1992, conventional sampling techniques were used at the site, which consisted of bailing or pumping three well volumes and then collecting the sample. In 1992, the sampling protocol was changed to purging with either a submersible pump or a peristaltic pump until the turbidity stabilized and then sampling. In March 1993, all nine point-of-compliance (POC) wells were converted to LF sampling with dedicated bladder pumps positioned within the screened interval. The LF discharge 
rate was 0.1 to $0.2 \mathrm{~L}$ per minute. For all three techniques, all samples were collected without filtering.

The site's list of monitoring parameters was developed prior to LF conversion and was based on sampling events during which ground water was analyzed for the EPA Appendix IX constituents (40 CFR Part 264) [1993]). This resulted in parameters such as chromium and vanadium being included on the parameter list when, in fact, these parameters are naturally occurring in the aquifer and are unrelated to the contaminant plume (Whitehouse, 1995).

It is stated in the paper that samples collected by another consulting group before 1992 were reportedly "silty" and in many cases contained noticeable quantities of sediment. The authors recognized the potential for suspended solids in those samples to contribute to the presence of some of the non-plume-related constituents and concluded that a sampling method should be implemented that minimized suspended solids in the samples. Therefore, in October 1992, two of the POC wells were sampled using peristaltic and submersible pumps and purged until the ground water turbidity stabilized. Analytical results from this sampling event showed a nearly 90 percent decrease in certain constituents, including chromium and vanadium. In March 1993, all nine POC wells were converted to LF sampling with dedicated bladder pumps. Analytical results reported for seven subsequent quarterly monitoring events showed consistently low constituent concentrations and low variability among the seven sampling rounds.

Upon conversion to sampling methods that minimized turbidity (the turbidity stabilization sampling method and LF sampling with dedicated pumps), a number of chemical constituents initially placed on the monitoring parameter list under EPA Appendix IX were not detected over multiple sampling events. This significant reduction in analytical concentrations resulted in regulatory approval to remove dioxins, dibenzofurans, beta-hexachlorocyclohexane, cadmium, lead, and mercury from the ground water monitoring program, resulting in savings of hundreds of thousands of dollars (Whitehouse, 1995).

\subsubsection{Value and limitations of the Canterbury study results for the UMTRA Project}

The downward shift in constituent concentrations described above corresponds to Figure 2.1C of this report. These results provide evidence that LF sampling may cause a downward shift in detectable contaminant concentrations when compared to traditional methods. The lower analytical variability is similar to that shown in Figure 2.1E. Such a downward shift in constituent concentrations could impact UMTRA decisions, especially those relating to POC contamination and MCLs.

The effects of the LF conversion are not expected to be so apparent on UMTRA sites, because the UMTRA sampling protocol requires filtering the samples.

Filtering eliminates highly turbid samples that are the apparent cause of some of the elevated contaminant concentrations at the Canterbury site. Nevertheless, 
evidence is provided in the Canterbury paper that turbidity can affect analytical results. If the UMTRA Project eliminates the filtering protocol, the difference between traditional and LF sampling results could be much greater.

The Canterbury paper also documents additional evidence that the LF method is acceptable to regulatory agencies. According to the authors, a LF sampling conversion plan was submitted to the EPA for review and approval prior to the conversion. The plan was approved by EPA, and the site consultants implemented the method in all nine of the POC wells. It is stated in the paper that after a series of sampling rounds during which some parameters were not detected, these parameters were removed from the ground water monitoring program. Although not specifically stated in the paper, the EPA must have approved the removal of these parameters from the monitoring list. This indicates that the EPA recognizes the LF analytical results as valid representations of aquifer water even if the LF results are lower than those found by traditional sampling methods.

Perhaps the most significant aspect of the Canterbury paper is that it documents the first known case where conversion to LF sampling was used as a monitoring strategy with a specific expected outcome rather than simply as an economical sampling method. The LF method was selected because it would provide samples with lower turbidity, resulting in lower reported concentrations of nuisance background constituents. This outcome was achieved on the Canterbury site, and this case suggests that similar strategies could be implemented on other environmental sites. Such a strategy can be misused if LF sampling is implemented to cause artificially low parameter concentrations in ground water samples, or even if that appears to be the objective. However, as long as the LF method is recognized as providing samples that are actually more representative of ground water conditions compared to traditional methods, regulators, clients, and consultants should avail themselves of the LF method.

\subsection{U.S. ENVIRONMENTAL PROTECTION AGENCY GROUND WATER SAMPLING - A WORKSHOP SUMMARY, EPA/600/R-94/205}

A recent paper entitled $A$ Study of the Impact of Monitoring Well Purging and Filtering Techniques on Metals Concentrations in Groundwater Samples from the Auburn Road Landfill Site in Londonderry, N. H., by Carol White (EPA, 1993b), contained the results of an investigation of iron and arsenic contamination at a New Hampshire landfill.

Analytical results were compared from concurrent pairs of filtered and unfiltered samples collected from 52 wells by the LF method. Arsenic concentrations in ground water at the site ranged from approximately $0.02 \mathrm{mg} / \mathrm{L}$ to $0.5 \mathrm{mg} / \mathrm{L}$. Iron concentrations were also quite variable, ranging from less than $0.1 \mathrm{mg} / \mathrm{L}$ to over $100 \mathrm{mg} / \mathrm{L}$. Arsenic results showed no tendency for unfiltered samples to yield higher concentrations than filtered samples. The filtered and unfiltered iron results also correlated very well when concentrations were relatively high (above $1 \mathrm{mg} / \mathrm{L}$ ). 
At lower concentrations, unfiltered results were generally higher than filtered results. These results suggest that constituent levels may be relatively unaffected by filtration of samples collected by the LF method. The study did not include an evaluation of effects of filtration of samples collected using a high flow purge for comparison to the LF results.

Concentrations of arsenic and iron were also compared in filtered samples collected with a high flow purge rate ( $>0.5 \mathrm{~L}$ per minute) to unfiltered LF samples $(0.2$ to $0.3 \mathrm{~L}$ per minute). The comparison was restricted to one sampling round on three wells. In all cases, the filtered samples obtained with a high flow rate method yielded higher iron and arsenic concentrations than the unfiltered, LF rate samples. The data suggest that the high flow rate sampling method may mobilize particles that can pass through a 0.45 -micron filter into the water sample, resulting in elevated concentrations of metals. However, graphs presented in the paper indicate that the differences were generally less than 10 percent, and that the observed differences associated with sampling method were smaller than the observed differences in water quality measurements from one sampling round to the next.

In another study presented in the EPA workshop summary, You Can't Always Get What You Want But You Can Get What You Need, by Jack Connelly (EPA, 1993c), employees of the state of Wisconsin compared analytical results from ground water samples collected by bailing and filtering versus LF sampling without filtering. The study site was a Wisconsin landfill and the analysis suite included arsenic, cadmium, chromium, and lead.

The following concentrations were measured from one sampling round from a single background well at a foundry site (Table 3.4).

Table 3.4 Low flow and bailer sampling comparison $(\mu \mathrm{g} / \mathrm{L})$

\begin{tabular}{lcccc}
\hline Analyte & MCL & $\begin{array}{c}\text { Bailer } \\
\text { unfiltered }\end{array}$ & $\begin{array}{c}\text { Bailer } \\
\text { filtered }\end{array}$ & $\begin{array}{c}\text { LF } \\
\text { unfiltered }\end{array}$ \\
\hline Arsenic & 50 & 120 & $<2$ & $<1$ \\
Cadmium & 5 & 9.2 & $<0.5$ & 0.29 \\
Chromium & 100 & 450 & $<2$ & 1.2 \\
Lead & 15 & 320 & $<5$ & $<1$ \\
\hline
\end{tabular}

LF - low flow

$M C L$ - maximum concentration level

$\mu g / L$ - micrograms per liter

From EPA, 1993c 
The data in this table show that bailed unfiltered water samples contain significantly higher contaminant concentrations than either bailed filtered samples or LF unfiltered samples. According to the author, the higher metal concentrations found in the bailed samples are the result of higher turbidity in the sample, including colloidal material. The higher turbidity is an artifact of the plunging motion of the bailer pulling solid or colloidal aquifer material through the well screen. These data suggest that LF sampling, with or without filtering, produces samples with lower turbidity than bailing, resulting in lower metals concentrations regardless of the metal source.

Analytical results from one sampling round are also presented for chromium from two wells: the first with relatively low levels of chromium and the second with high levels. Table 3.5 shows the data and collection methods.

Table 3.5 Low flow and bailer sampling comparison of chromium $(\mu \mathrm{g} / \mathrm{L})$

\begin{tabular}{|c|c|c|c|c|}
\hline \multicolumn{3}{|c|}{ Well P-3 } & \multicolumn{2}{|c|}{ Well P-4 } \\
\hline $\begin{array}{c}\text { Bailer } \\
\text { unfiltered }\end{array}$ & $\begin{array}{c}\text { Bailer } \\
\text { filtered }\end{array}$ & $\begin{array}{c}\text { LF } \\
\text { unfiltered }\end{array}$ & $\begin{array}{l}\text { Bailer } \\
\text { filtered }\end{array}$ & $\begin{array}{c}\mathrm{LF} \\
\text { unfiltered }\end{array}$ \\
\hline 77 & 20 & 14 & 470 & 292 \\
\hline
\end{tabular}

$\mu \mathrm{g} / \mathrm{L}$ - micrograms per liter

From EPA, 1993c.

These data suggest that LF sampling produces lower analyte concentrations than either filtered or unfiltered bailing.

\subsection{SUMMARY OF THE LITERATURE CONCLUSIONS}

The 1993 Kearl paper compared traditional and LF sampling at a site in Kansas City, Missouri, using the paired t-test. The practical differences in analytical results from unfiltered samples were generally small. Hydrogeologic conditions such as well depth, low hydraulic conductivity, a clayey aquifer, and reducing subsurface conditions were identified as possibly having more impact on sampling results than the sampling technique.

In the 1994 Kearl paper, the same analytical data from Kansas City were evaluated using the nonparametric sign test. Only 5 of the 27 inorganic result differences were significant at the 0.05 level of significance but all 5 significant results occurred in the same well and, in each case, LF sampling results were higher than the MBV results. Analytical results were also discussed from repeated LF sampling at a site in Paducah, Kentucky. This comparison showed only minor differences between LF sampling events. The authors recommended additional study. 
In the Kearl papers, turbidity is identified as a factor that may impact analytical results. Zinc concentrations were also pointed out as being lower with LF sampling than with MBV, possibly due to lower turbidity. However, two wells showed higher concentrations of iron in the LF samples than in the MBV samples. In one well, iron concentrations sampled by the LF method were nearly $40 \mathrm{mg} / \mathrm{L}$ higher than concentrations in the MBV samples.

In the Fernald study (Shanklin, 1993), the author presents a comparison of LF and MBV sampling methods in four wells. Waste minimization and time savings were achieved by converting to the LF method in those four wells, resulting in an annual cost reduction of approximately $\$ 115,000$.

Mean iron concentrations were consistently higher in the Fernald study in the unfiltered LF samples compared to unfiltered MBV samples. However, the increases are not significant from a human health risk standpoint because observed iron concentrations fall within the normal dietary range. Filtered LF and MBV iron concentrations were nearly identical. Uranium was a measured parameter in the Fernald study, but the concentrations in three of the four wells were so low in both LF and MBV samples that the results are of little use to UMTRA.

The Fernald study authors conclude that there will be little difference between the analytical results of the LF and MBV sampling methods. The study is of particular interest to UMTRA because it provides an example of a DOE site where LF sampling has saved time and money, with no negative impact on analytical results.

The Canterbury paper (Hurley and Whitehouse, 1995) documents conversion to LF sampling in nine POC wells on a Connecticut NPL site. Prior to the conversion, the wells were sampled by several traditional methods, including bailing, which resulted in turbid samples. EPA protocols required the samples to be unfiltered, and the consultants in charge of the sampling program determined that suspended solids and colloidal particles in the samples might be the cause of elevated contaminant concentrations.

Although LF sampling is discussed in detail in the paper, we interpret the study to show that reducing turbidity by any means, including LF sampling with dedicated pumps, may significantly reduce contaminant concentrations in unfiltered samples. By using LF sampling over approximately two years and demonstrating that some constituents were no longer detectable, the consultants succeeded in having a number of parameters removed from the monitoring list and consequently saved their client many thousands of dollars in analytical costs.

Furthermore, the Canterbury site study is the first known account of LF sampling being used as a strategy to eliminate analytical parameters from a regulatory (EPA) ground water monitoring list. This implies that the EPA acknowledges the validity of LF sampling results, even if those results are different from results gained from previous sampling techniques. This suggests that in the EPA's opinion, LF sampling 
produces samples that are more representative of actual ground water conditions than samples obtained using traditional methods.

The New Hampshire study (EPA, 1993b) consisted of two parts. The first part was conducted in 1991 and compared analytical results from filtered and unfiltered LF sampling. Results of the study indicated excellent correlation between the two methods for both arsenic and iron, although iron concentrations were near the analytical detection limits. The second part of the study, conducted in 1992, compared unfiltered LF sampling with filtered high flow rate (MBV) sampling. In all cases, the unfiltered LF sampling results yielded lower arsenic and iron results than the filtered high flow sampling. However, the differences were generally less than 10 percent, which was much less than the variation seen in concentrations in separate sampling events.

In the study prepared by Connelly (EPA, 1993c), filtered and unfiltered bailed samples were compared with unfiltered LF samples. In most cases the unfiltered LF results were lower than either the filtered or unfiltered bailed samples. The author attributes this difference to lower turbidity in the LF samples. 


\subsection{EVALUATION OF THE UMTRA PROJECT LOW FLOW SAMPLING DATA}

The first round of chemical analysis data from filtered samples collected using the LF system were recently received from the laboratory. Results have been entered into the UMTRA Project water quality data base (Software Program for Environmental Analysis and Reporting [SPEAR]) (DOE, 1992) and are undergoing standard data validation. In addition to the standard $Q A$, all of the new ground water data for Green River, Durango Bodo Canyon, and Monument Valley were run through the new suspected anomalies report program. The program was designed to identify potential anomalies among the newly acquired chemical analysis data by comparing those new values to measurements from previous sampling rounds, after making adjustments for possible time trends in concentration levels, historical outliers, and nondetected concentrations in the historical data base. Data flagged by the program are, to some degree, different from what the older data from the well would predict.

The suspected anomalies program may be useful in identifying sudden changes in water quality associated with the transition from MBV to LF sampling. However, program results will need to be interpreted with care, because there are a number of alternative explanations for unusual measurements among newly acquired data. They may arise from any combination of random and systematic errors introduced during the water collection, transit, laboratory analysis, and recording or data entry phases of the water sampling and analysis event or actual changes in the aquifer.

Table 4.1 presents the results of the suspected anomalies program for key UMTRA Project constituents analyzed for during the first round of LF sampling at the three UMTRA Project sites. Site wells that were sampled using the traditional $3 B V$, as well as those sampled using LF, are included in the evaluation. No obvious patterns among $L F$ well results can be seen from the results. It should be noted that approximately the same percentage of the new LF data and new 3BV data were flagged as potential anomalies by the report and that both low and high anomalies occur for both sampling methods. There is little that can be concluded based on one round of data. The impact of LF sampling may vary between wells. In addition, the impacts of LF sampling may be small compared to the other sources of data variability. Only time and additional sampling will provide a more definitive answer. 
Table 4.1 Results of suspected anomalies program for low flow and multiple bore volume wells, sampled at three UMTRA Project sites

\begin{tabular}{|c|c|c|c|c|c|c|c|c|c|c|c|c|c|c|c|}
\hline \multirow{7}{*}{ 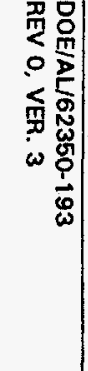 } & Site & Method & ID & $\mathrm{Ca}$ & $\mathrm{Na}$ & $\mathrm{Cl}$ & $\mathrm{SO}_{4}$ & TDS & $\mathrm{NO}_{3}$ & $\mathrm{Fe}$ & Mn & Mo & Ra-226 & $\mathrm{Se}$ & U \\
\hline & \multirow{6}{*}{$\begin{array}{l}\text { DUR-03 } \\
10 / 94^{\mathrm{a}} \\
3 / 27 / 95^{\mathrm{b}}\end{array}$} & \multirow[t]{5}{*}{ LF } & 605 & & & $L$ & & $L$ & NA & & & & & & \\
\hline & & & 607 & & & & & & NA & & $\mathrm{H}$ & & & & \\
\hline & & & 608 & & & & & & NA & & & & & & \\
\hline & & & 612 & $\mathrm{H}$ & & & $\mathrm{H}$ & & NA & $\mathrm{H}$ & $\mathrm{H}$ & & $\mathrm{H}$ & & \\
\hline & & & 621 & & & & & & NA & $\mathrm{H}$ & $\mathrm{H}$ & & & & \\
\hline & & MBV & 623 & $\mathrm{H}$ & $\mathrm{H}$ & & $\mathrm{H}$ & $\mathrm{H}$ & NA & & $\mathrm{H}$ & & & & \\
\hline & \multirow{13}{*}{$\begin{array}{l}\text { MON-01 } \\
12 / 94^{\mathrm{a}} \\
3 / 31 / 95^{\mathrm{b}}\end{array}$} & \multirow[t]{5}{*}{ LF } & 651 & & & $\mathrm{~L}$ & $L$ & & & & & & & NA & \\
\hline & & & 659 & & & L & L & L & & & & & & NA & \\
\hline & & & 660 & & & & $L$ & & & & & & & NA & \\
\hline & & & 663 & & & $L$ & & & & & $L$ & & & NA & \\
\hline & & & 664 & $L$ & $\mathrm{H}$ & & & & & & & $L$ & & NA & $L$ \\
\hline & & \multirow[t]{8}{*}{ MBV } & 606 & $\mathrm{H}$ & & & & $\bar{H}$ & & & $\mathrm{H}$ & & & NA & \\
\hline & & & 613 & $\mathrm{H}$ & $\mathrm{H}$ & NA & NA & & & & & & & NA & \\
\hline & & & 614 & $\mathrm{H}$ & $\mathrm{H}$ & & & & & & & & & NA & $L$ \\
\hline & & & 617 & $\mathrm{H}$ & $H$ & NA & NA & $L$ & & & & & & NA & \\
\hline & & & 625 & $\mathrm{H}$ & $\mathrm{H}$ & NA & NA & $L$ & & & & & & NA & \\
\hline & & & 652 & & & $L$ & $L$ & & & & & & & NA & $\mathrm{L}$ \\
\hline & & & 653 & & & $L$ & & & & & & & & NA & $\mathrm{L}$ \\
\hline & & & 657 & & & $L$ & & & & & & & & NA & $L$ \\
\hline \multirow{11}{*}{\multicolumn{2}{|c|}{$\begin{array}{l}\text { GRN-01 } \\
1 / 95^{a} \\
3 / 27 / 95^{b}\end{array}$}} & \multirow[t]{6}{*}{ LF } & 171 & & & $\mathrm{H}$ & & $\mathrm{H}$ & $\mathrm{H}$ & $\mathrm{L}$ & $L$ & $\mathrm{H}$ & & & $\mathrm{H}$ \\
\hline & & & 173 & & & & & & & & & & & & \\
\hline & & & 174 & $L$ & & & $L$ & $L$ & & & $\bar{L}$ & & & & \\
\hline & & & 176 & $\mathrm{H}$ & $L$ & $H$ & & $\mathrm{H}$ & $\mathrm{H}$ & & $L$ & $L$ & & $\mathrm{H}$ & $\mathrm{L}$ \\
\hline & & & 179 & $\mathrm{~L}$ & & & & & & & & & & & \\
\hline & & & 813 & $L$ & & $\mathrm{H}$ & & & & $\mathrm{H}$ & & & & & $\mathrm{L}$ \\
\hline & & \multirow[t]{5}{*}{ MBV } & 172 & & & & $\mathrm{H}$ & $\mathrm{H}$ & $\mathrm{H}$ & & $\mathrm{H}$ & & & & \\
\hline & & & 175 & & & & $L$ & & & & & $L$ & $L$ & & \\
\hline & & & 177 & $\mathrm{H}$ & & & $L$ & & $\mathrm{H}$ & & & & & & \\
\hline & & & 178 & & & L & $L$ & $L$ & & $\mathrm{H}$ & & & & & \\
\hline & & & 180 & $\mathrm{H}$ & & & & $L$ & & $\mathrm{H}$ & & & & & \\
\hline
\end{tabular}

NA - filtered samples were not analyzed for this constituent.

Note: Data validation not complete. 


\subsection{CONCLUSIONS}

How likely is it that LF sampling could significantly impact the UMTRA Project water quality data base? The results of comparison studies and LF conversions in the literature suggest that concentrations of some constituents would drop, especially in unfiltered samples. In particular, concentration shifts might be expected in wells that had previously been sampled by aggressive traditional methods such as bailing. However, in spite of the recent LF literature, we cannot say for sure that conversion to LF on any of the UMTRA sites would result in the same trends seen in the literature.

The literature reviewed in this report and the limited UMTRA LF data collected to date provide at least some answers to the questions posed in Section 1 of this report.

- How different are the water results between MBV and LF samples? The literature suggests that LF samples will have lower metal concentrations and that the differences will be small, probably less than 10 percent for most constituents, especially in filtered samples. The UMTRA Project collects both filtered and unfiltered samples; however, filtered samples predominate. Thus, we would expect few, if any, major constituent concentration shifts in wells converted to the LF method. Iron analyses may be less predictable because of sensitivity to the oxidation/reduction state of the ground water.

- Are the differences predictable? Generally, we can predict that the differences will be small for filtered samples, but larger for samples that have been collected by agressive, turbidity producing sampling methods such as bailing. Most of the UMTRA wells that have been converted to LF have not been bailed in the past, so we expect little difference in those wells. Likewise, the wells we expect to convert to LF in the future are those that have historically not been bailed, so we expect little difference in analytical results from those wells after the conversion to LF.

- Are certain constituents affected more than others? The literature suggests that among the constituents of interest to UMTRA, only iron appeared to be more affected than other parameters. Other parameters of interest to UMTRA, such as uranium, were not addressed adequately in the literature.

- Does the hydrogeologic environment impact the magnitude of the differences between LF and MBV analytical results? According to findings in the current literature, geochemical factors such as oxidizing or reducing conditions in the aquifer may impact the analytical results more than or together with the sampling method. Also, the type of formation (fine or coarse grained), the aquifer recharge capacity, the type of well completion, and other factors may influence the quantity of particulates or colloids present in the well at the time of sampling, which can impact the analytical results.

Because we do not have complete answers to the questions presented above, the UMTRA Project has the opportunity to contribute valuable new information to the scientific community as it proceeds with its conversion from traditional to LF sampling. 


\subsection{OPTIONS}

The program may proceed in one of three ways.

\section{Option 1}

Under the regular sampling schedule, collect a few more rounds of data from the wells that have already been converted to the LF method before expansion of the LF program. There are positive features about this approach. If differences in water quality became apparent at the initial sites, the information could guide the Project in later expansion of the program. For example, it has already been learned at Green River that 4 of the 11 wells have inadequate recharge for LF sampling. This hydrogeologic limitation could be better recognized in the future and the dedicated pumps could be used elsewhere. However, this option has its drawbacks. Most of the wells at Green River are showing time trends (an increase or decrease in contaminant concentrations over a period of several sampling rounds) in water quality. These trends will make it more difficult to evaluate the new sampling method. Assuming at most semiannual sampling, conclusions and recommendations for LF sampling may not be available for several years.

\section{Option 2}

The second option is for the UMTRA Project to conduct a field comparison similar to that previously conducted by Kearl, but focusing on constituents of particular interest to the UMTRA Project. The TAC had at one time proposed that such a study be conducted at Shiprock, New Mexico. The field study would involve collecting water samples on the same day using both sampling methods: the LF method, followed by the traditional 3BV purge method. This could be done using several wells at the site and could be repeated at short intervals during a year. Shiprock has the advantage of being relatively close to Albuquerque, which minimizes transportation costs, and also has wells screened in two very different hydrogeological units, the terrace bedrock and the San Juan River alluvium. The study would provide preliminary information on the potential impacts of LF sampling on measured concentrations of key UMTRA Project contaminants in less than a year.

One advantage of this study over the Option 1 is that results should be valid even in the presence of time trends. The most positive feature of the field study, however, is that the concurrent sampling design may provide much greater precision for comparing the effects of the sampling method on water quality measurements. The reason this works is that much of the temporal variation is eliminated when both types of samples are taken on the same day. In other words, each type of sample will access essentially the same ground water, as opposed to sampling months or years apart, where ground water conditions may be markedly different due to plume migration or other factors. In addition, the water samples 
are shipped together to the laboratory and are analyzed at the same time, thus minimizing laboratory performance variations.

\section{Option 3}

Continue conversion of additional wells from the traditional methods to the LF method and monitor the results as they become available. Implement a site-specific comparison study as described in Option 2 if and when the need arises. For example, if a water quality shift occurs in LF wells, then a comparison study can be conducted in those wells. This option would defer the cost of the study until it was actually required and would focus the study on those constituents impacted by the change in sampling methods at that particular site.

\subsection{RECOMMENDATIONS}

Based on what we have learned from this literature review and analysis, there is no conclusive evidence that contaminant concentration sampling results would systematically increase or decrease in UMTRA wells as a result of the LF conversion. It appears that the presence of solids or colloidal particles may play an important role in finding elevated contaminant concentrations in ground water samples. Reducing the turbidity in the samples, by filtering, or preferably by a sampling method that minimizes turbidity, may result in lower contaminant concentrations.

The EPA (at the Canterbury site) and the DOE (at the Fernald site) have approved the LF method and acknowledged that lowering detectable contaminant concentrations by using the LF method is technically valid, because the samples are representative of actual ground water conditions. At Canterbury, LF was used as a monitoring strategy specifically to reduce or eliminate detection of certain constituents, resulting in the removal of some constituents from the monitoring program.

The literature reviewed in this paper suggests that conversion to LF sampling will cause no systematic, uniform, or predictable shift in analytical results. The shifts that are documented in the literature appear to be the result of factors such as lowering the turbidity in the sample, hydrogeology, oxidation-reduction state of the ground water, or other site-specific conditions. Of the six papers reviewed, none demonstrated any statistically significant analytical shift for filtered ground water samples. Based on the current literature, the impact of LF sampling overall appears to be minimal, with a few different results that are site-specific and unpredictable.

Furthermore, we believe that the results of a comparison study on a specific UMTRA site would not necessarily apply to any other UMTRA site, and a general comparison study on a single UMTRA site would have little benefit to the Project. 
For these reasons, we believe that an UMTRA site-specific study is not necessary at this time. We recommend Option 3, in which a site-specific study can be implemented at any time on any site if a significant shift in analytical results occurs. We further recommend continued conversion to LF sampling in selected wells (those with sufficient recharge, especially large volume wells) throughout the UMTRA Project. 
UMTRA GROUND WATER SAMPLING TECHNIQUES: COMPARISON OF THE TRADITIONAL AND LOW FLOW METHODS

\subsection{LIST OF CONTRIBUTORS}

\begin{tabular}{ll}
\hline Name & Contribution \\
\hline R. Sengebush & Author, document coordinator \\
K. Smith & Co-author \\
R. Saar & Document review \\
WordCenter, Inc. & Text processing \\
J. Jones & Technical editing \\
\hline
\end{tabular}




\subsection{REFERENCES}

DOE (U.S. Department of Energy), 1992. Software Program for Environmental Analysis and Reporting (SPEAR) System, U.S. Department of Energy, UMTRA Project Office, Albuquerque Operations Office, Albuquerque, New Mexico.

EPA (U.S. Environmental Protection Agency), 1993a. EPA Ground Water Sampling - A Workshop Summary, EPA/600/R-94/205, Dallas, Texas, November 30-December 2, 1993.

EPA (U.S. Environmental Protection Agency), 1993b. "A Study of the Impact of Monitoring Well Purging and Filtering Techniques on Metals Concentrations in Groundwater Samples from the Auburn Road Landfill Site in Londonderry, N. H.," prepared by Carol White for EPA Ground Water Sampling - A Workshop Summary, EPA/600/R-94/205, Dallas, Texas, November 30-December 2, 1993.

EPA (U.S. Environmental Protection Agency), 1993c. "You Can't Always Get What You Want But You Can Get What You Need," prepared by Jack Connelly for EPA Ground Water Sampling - A Workshop Summary, EPA/600/R-94/205, Dallas, Texas, November 30-December 2, 1993.

EPA (U.S. Environmental Protection Agency), 1986. RCRA Ground Water Monitoring Technical Enforcement Guidance Document, U.S. Department of Commerce, National Technical Information Service, Washington, D.C.

Fenn et al. (Fenn, D., E. Cocozza, J. Isbiter, O. Braids, B. Yare, and P. Roux), 1977. Procedures Manual for Ground Water Monitoring at Solid Waste Disposal Facilities. U.S. Environmental Protection Agency, EPA/530/SW-611. p. 260.

Gibb et al. (Gibb, J. P., R. M. Schuller, and R. A. Griffin), 1981. Procedures for the Collection of Representative Water Quality Data from Monitoring Wells. Cooperative Groundwater Report 7, Illinois State Water and Geological Surveys, p. 61.

Hurley, D., and J. Whitehouse, 1995. "ACL Monitoring Using a Low-Flow Sampling Technique, A Case Study," in Proceedings of the Ninth National Outdoor Action Conference and Exposition, 1995, Las Vegas, Nevada.

JEG (Jacobs Engineering Group Inc.), n.d. Albuquerque Operations Manual, standard operating procedures, prepared by Jacobs Engineering Group Inc., Albuquerque, New Mexico, for the U.S. Department of Energy, UMTRA Project Office, Albuquerque Operations Office, Albuquerque, New Mexico.

Kearl et al. (Kearl, P. M., N. E. Korte, M. Stites, and J. Baker), 1994. "Field Comparison of Micropurging vs. Traditional Ground Water Sampling" in Ground Water Monitoring Review, Fall 1994, pp. 183-190. 
Kearl et al. (Kearl, P. M., N. E. Korte, and T. A. Cronk), 1993. Field Comparison of Micropurging Versus Traditional Groundwater Sampling, presented at Environmental Remediation Conference 1993, Augusta, Georgia.

Kearl et al. (Kearl, P. M., N. E. Korte, and T. A. Cronk), 1992. Suggested Modifications to Ground Water Sampling Procedures Based on Observations From the Colloidal Borescope in Ground Water Monitoring Review 12, no. 2: pp. 155-61.

Powell, R. W., and R. W. Puls, 1993. Passive Sampling of Ground Water Monitoring Wells Without Purging: Multi-level Well Chemistry and Tracer Disappearance, in Journal of Contaminant Hydrology 12, pp. 51-77.

Robin, M. J. L., and R. W. Gillham, 1987. Field Evaluation on Well Purging Procedures in Ground Water Monitoring Review 7, no. 4, pp. 85-93.

Schuller et al. (Schuller, R. M., J. P. Gibb, J. P., and R. A. Griffin), 1981. Recommended Sampling Procedures for Monitoring Wells in Ground Water Monitoring Review, v. 1 , no. 1 , pp. $42-46$.

Shanklin, D., 1995. Personal communication with R. Sengebush, Jacobs Engineering Group Inc., UPDCC File Location No. 0.19.2.5.3, 10 May 1995.

Shanklin, D., 1993. Waste Minimization and Groundwater Sampling Efficiency: A New Technique for Purging Groundwater Monitoring Wells at the Fernald Environmental Management Project, prepared by the U.S. Department of Energy, Fernald Environmental Restoration Management Corporation, Cincinnati, Ohio.

Whitehouse, J., 1995. Fuss and O'Neill, Inc., personal communication with R. Sengebush, Jacobs Engineering Group Inc., UPDCC File Location No. 0.19.2.5.3, 1 June 1995.

\section{CODE OF FEDERAL REGULATIONS}

40 CFR Part 264, Appendix IX, Standards for Owners and Operators of Hazardous Waste Treatment, Storage, and Disposal Facilities, Ground-Water Monitoring List, U.S. Environmental Protection Agency (1993). 